\title{
Facile Synthesis of Highly Aligned Multiwalled Carbon Nanotubes from Polymer Precursors
}

\author{
Catherine Y. Han, ${ }^{1,2}$ Zhi-Li Xiao, ${ }^{1,3}$ H. Hau Wang, ${ }^{1}$ Xiao-Min Lin, ${ }^{4}$ Susana Trasobares, ${ }^{1,5}$ \\ and Russell E. Cook ${ }^{1}$
}

${ }^{1}$ Materials Science Division, Argonne National Laboratory, Argonne, IL 60439, USA
${ }^{2}$ Physical Science Department, Richard J. Daley College, Chicago, IL 60652, USA
${ }^{3}$ Department of Physics, Northern Illinois University, DeKalb, IL 60115, USA
${ }^{4}$ Center for Nanoscale Materials, Argonne National Laboratory, Argonne, IL 60439, USA
${ }^{5}$ Departamento de Ciencia de Materiales, Universidad de Cadiz, Puerto Real 11510 Cadiz, Spain

Correspondence should be addressed to H. Hau Wang, hau.wang@anl.gov

Received 11 November 2008; Accepted 25 February 2009

Recommended by Jun Liu

\begin{abstract}
We report a facile one-step approach which involves no flammable gas, no catalyst, and no in situ polymerization for the preparation of well-aligned carbon nanotube array. A polymer precursor is placed on top of an anodized aluminum oxide (AAO) membrane containing regular nanopore arrays, and slow heating under Ar flow allows the molten polymer to wet the template through adhesive force. The polymer spread into the nanopores of the template to form polymer nanotubes. Upon carbonization the resulting multi-walled carbon nanotubes duplicate the nanopores morphology precisely. The process is demonstrated for 230, 50, and $20 \mathrm{~nm}$ pore membranes. The synthesized carbon nanotubes are characterized with scanning/transmission electron microscopies, Raman spectroscopy, and resistive measurements. Convenient functionalization of the nanotubes with this method is demonstrated through premixing CoPt nanoparticles in the polymer precursors.
\end{abstract}

Copyright ( 2009 Catherine Y. Han et al. This is an open access article distributed under the Creative Commons Attribution License, which permits unrestricted use, distribution, and reproduction in any medium, provided the original work is properly cited.

\section{Introduction}

The discovery of carbon nanotubes (CNTs) by Iijima in 1991 opened up a brand new era in materials science and nanotechnology [1]. The intrinsic electronic properties of single-walled carbon nanotubes are such that they may be metallic or semiconductive depending on their diameter and the graphitic ring arrangement around the tube wall [2]. Furthermore, CNTs show exceptionally good thermal and mechanical properties. It is expected that CNTs could solve the thermal dissipation problem of nanodevices due to their high thermal conductivity. CNTs can transport significant amount of electric current without doping problem encountered in Si-based FETs (field effect transistors) because of the graphitic nature, and the covalent bonds among carbon atoms are much stronger. CNTs are among the most promising materials anticipated to impact future nanotechnology due to their unique structural and electronic properties, which have generated great interest for application in a broad range of potential nanodevices. The unique properties of CNTs have led to the study of their use in areas as diverse as sensors [3], electrochemical actuators [4], nanoelectronics [5], field-emitting flat panel displays [6], battery [7], scanning probe microscopy tips [8-10], FETs $[11,12]$, gas storages [13], and so forth.

Extensive efforts have been made to control the growth and properties of CNT since their discovery in 1991 [1]. Large quantities of carbon nanotubes can now be produced by arc discharge [14], laser ablation [15], chemical vapor deposition methods [16-20], or flame synthesis [21-24]. However, the applications of CNTs have been limited because of problems in catalyst residues, difficulty with the alignment, diameter uniformity of the nanotubes mixed metallic and semiconductive properties, and so forth [21]. One of the most efficient approaches to the production of large areas of highly ordered, isolated long CNTs with monodispersed 
tube diameter and length is based on template-confined growth of CNTs. The diameter, length, and packing density of CNTs can be ideally controlled when the nanotube arrays are fabricated in porous anodic aluminum oxide (AAO) templates [16, 25-27]. Furthermore, porous AAO templates with well-controlled 3D channel structures such as dumbbell shaped [28], linearly joined [29,30], Y-branched [31] as well as novel dendriform have been prepared and used to grow well-aligned arrays of CNTs through the chemical vapor deposition method [32]. Pyrolysis of gaseous hydrocarbons such as $\mathrm{C}_{2} \mathrm{H}_{2}, \mathrm{C}_{2} \mathrm{H}_{4}$, and $\mathrm{C}_{3} \mathrm{H}_{6}$ in templates can be achieved with or without catalyst, but both processes require specialized reaction chamber, various gas supply, careful control of gas flow, pyrolyzing temperature higher than $650^{\circ} \mathrm{C}$, and costly safety equipments for highly flammable gases.

Graphitic nanotubes have also been synthesized by carbonization of the polyacrylonitrile [33] and poly(furfuryl alcohol) $[34,35]$ within the pores of AAO membranes at 600 and $900^{\circ} \mathrm{C}$, respectively. The synthesis is achieved by carbonization of polymers through a three-step approach: (1) monomers and initiators are infiltrated into the pores of AAO template, (2) the polymers are produced inside the pores of AAO template through polymerization, and (3) The CNTs are produced through carbonization of the polymers prepared in step (2). The whole process requires carefully controlled polymerization initiation and it is tedious and time consuming. No detailed structural characterization was reported in the first case [33], and bamboo and bubble structure were obtained for the latter [35].

Herein we report a convenient one-step approach for the preparation of well aligned carbon nanotube array. Commercially available polymers are used for the study. No catalyst and no monomer initiator are required. Comparing to pyrolysis of highly combustible gases, this method is simple and avoids many safety concerns. In addition, the asprepared aligned CNTs contain open pores that are ready for functionalization or filling with nanoparticles. Polymer nanotubes prepared with templates through melt-wetting in the 300 to $900 \mathrm{~nm}$ pore diameter region have been reported [36]. Due to the high viscosity nature of the polymers in general, whether the melt-wetting method works for much smaller pores has not been addressed. In this work, we explore templates with pore diameters between 230 and $20 \mathrm{~nm}$ with melt-wetting, and through carbonization at a moderate temperature we report good quality multi-walled carbon nanotubes (MWNTs) formation. Aligned CNTs with both ends open or with one end open and one end closed are presented here.

\section{Experimental}

All chemicals and polymers are reagent grade from Aldrich Chemicals except the five-minutes epoxy (Devcon Corp.). Three types of porous anodic aluminum oxide (AAO) membranes are used as templates in this work. One is a commercially available membrane with $60 \mu \mathrm{m}$ thickness and $230 \mathrm{~nm}$ pore diameter (Whatman Ltd. , Anodisc $13 \mathrm{~mm}$ ) [37]. The other two are prepared by anodic oxidation of high purity aluminum plate (Alfa Aesar, 99.99\%, $0.25 \mathrm{~mm}$ thick) through a two-step anodization process that has been reported in literature $[38,39]$. The membranes are $60 \mu \mathrm{m}$ thick, and the pore diameters are 50 and $20 \mathrm{~nm}$, respectively. A typical procedure for polymer carbonization in AAO membrane is described here. Either solid or liquid polymers are placed on top of AAO templates $(\sim 25-30 \mathrm{mg}$ polymer per disk). The polymer over AAO template in an alumina boat is placed in a tube furnace (Lindberg). Ar is purged for $\sim 30$ minutes. Then the temperature is slowly increased at a rate of about $2^{\circ} \mathrm{C} / \mathrm{min}$ from ambient to the desired temperature (typically $600^{\circ} \mathrm{C}$ ). The temperature is kept constant for 3 hours under Ar flow to fully carbonize the polymer. The polymer slowly melts and spreads into the nanopores of the AAO template to form polymer nanotubes. Starting at a very low temperature of $\sim 400^{\circ} \mathrm{C}$, the polymers are carbonized, and graphitic nanotubes are generated. Thermal decomposition of small molecules and polymers is a complex reaction. We observe good Raman signals and the presence of MWNT with SEM from all blackened areas on AAO (vide infra). Therefore, we estimated the MWNT yield based on the starting reagent weight and the final weight gain on the AAO template. Typical yield is about $1 \%$ by weight.

The Raman measurements are carried out at room temperature with the use of a Raman microscope spectrometer (Renishaw, Ltd.) equipped with a $\mathrm{HeNe}$ laser $(632.8 \mathrm{~nm})$. A $180^{\circ}$ reflective geometry with the analyzer polarization parallel to the incident laser beam polarization is adopted. The spectrum is calibrated against a $\mathrm{Si}$ wafer standard $\left(520 \mathrm{~cm}^{-1}\right)$. The spectrum analysis is done with the use of Origin software. The UV-Raman measurement is carried out with the use of a frequency-doubled argon ion laser with excitation at $244 \mathrm{~nm}$. Typical spectrum is averaged over 10 scans. Field-emission scanning electron microscopy (FESEM) images are obtained on Hitachi S4700-II field emission SEM operating with an accelerating voltage of $10 \mathrm{kV}$. Transmission electron micrographs (TEM) and electron diffraction patterns are obtained on a Philips CM30T at $200 \mathrm{kV}$.

\section{Results and Discussion}

A range of polymers from very low molecular weight of a few hundred to medium size ones of $\sim 450 \mathrm{k}(\mathrm{g} / \mathrm{mol})$ has been applied in this study (Table 1). Regardless whether the polymer is solid or viscous liquid, upon heating all polymers melt at higher temperatures and the wetting phenomena between the polymers and AAO templates occur. The melts wet the membranes very well, and this is likely due to the fact that the cohesive force for complete filling of the nanopores is not as strong as the adhesive force for wetting the walls of the nanopores [36]. This wetting process leads to AAO membranes that are completely covered with polymers, and upon carbonization at temperature beyond $400^{\circ} \mathrm{C}$, the entire membrane is blackened. However, the faster rate of adhesive force must be properly balanced with a slower sample heating rate in order to allow sufficient 
TABLE 1: Polymer precursors and the resulting MWNT morphology and resistance.

\begin{tabular}{lccc}
\hline Polymers & $\mathrm{M}_{\mathrm{W}} \mathrm{g} / \mathrm{mol}$ & Resistance & Product morphology \\
\hline Poly(bisphenol A-co-epichlorohydrin) glycidyl ether & 355 & $20 \mathrm{k} \Omega$ & MWNTs \\
Bisphenol A propoxylate diglycidyl ether & 457 & $40 \mathrm{k} \Omega$ & MWNTs \\
Bisphenol A ethoxylate dimethacrylate & 1,700 & $6 \mathrm{k} \Omega$ & MWNTs \\
Poly(ethylene glycol) methyl ether & $2 \mathrm{k}$ & $7 \mathrm{M} \Omega$ & Not well formed \\
Polyisoprene & $40 \mathrm{k}$ & $1 \mathrm{M} \Omega$ & Not well formed, rubber-like \\
Polystyrene-co-poly(methyl methacrylate) & $100 \mathrm{k}-150 \mathrm{k}$ & $10 \mathrm{k} \Omega$ & MWNTs, some sponge-like features \\
PMMA & $120 \mathrm{k}$ & $25 \mathrm{k} \Omega$ & MWNTs \\
Polystyrene-b-polybutadiene & $140 \mathrm{k}$ & $300 \mathrm{k} \Omega$ & Flat collapsed tubes \\
PS polystyrene & $350 \mathrm{k}$ & - & Complete decomposition \\
Poly(acrylic acid) & $450 \mathrm{k}$ & $500 \mathrm{k} \Omega$ & Flat collapsed tubes
\end{tabular}

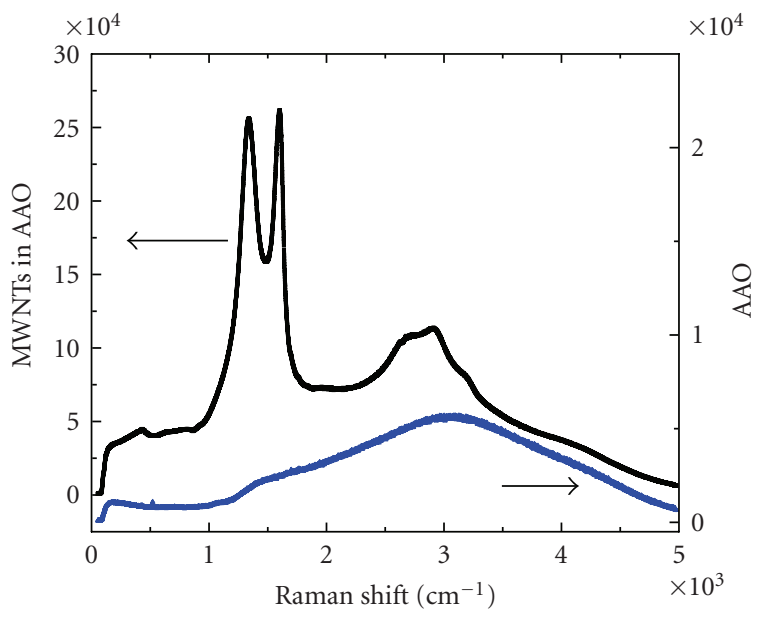

FIGURE 1: Typical Raman spectrum of carbonized polymer embedded in AAO membrane. The spectrum is signal averaged over 10 scans at room temperature.

flow and maximize the carbon nanotube formation. Typical sample heating rate in this study is $2^{\circ} \mathrm{C} / \mathrm{min}$. When higher heating rate such as $5^{\circ} \mathrm{C} / \mathrm{min}$ is used, the $\mathrm{AAO}$ membrane shows inhomogeneously darkened areas due to fast thermal decomposition of the melts. The blackened AAO membranes are subject to Raman, SEM, TEM, and conductivity measurements. Control experiment with use of polymers on flat substrate (nonporous alumina) upon carbonization fails to yield any CNTs. Sample characterization, the effects of different starting polymers, and preliminary results on incorporation of nanoparticles are presented below.

3.1. Raman Characterization. Raman spectroscopy has been used extensively for the characterization of multi-walled (MWNTs) and single-walled carbon nanotubes (SWNTs). The polymer/AAO membrane $(230 \mathrm{~nm})$ after carbonization at $600^{\circ} \mathrm{C}$ has been subjected to Raman studies (typical polymer, e.g., is bisphenol A ethoxylate dimethacrylate with $\mathrm{Mn} \sim 1700$ ). After carbonization at $600^{\circ} \mathrm{C}$ under Ar over three hours, the AAO membrane is completely black with

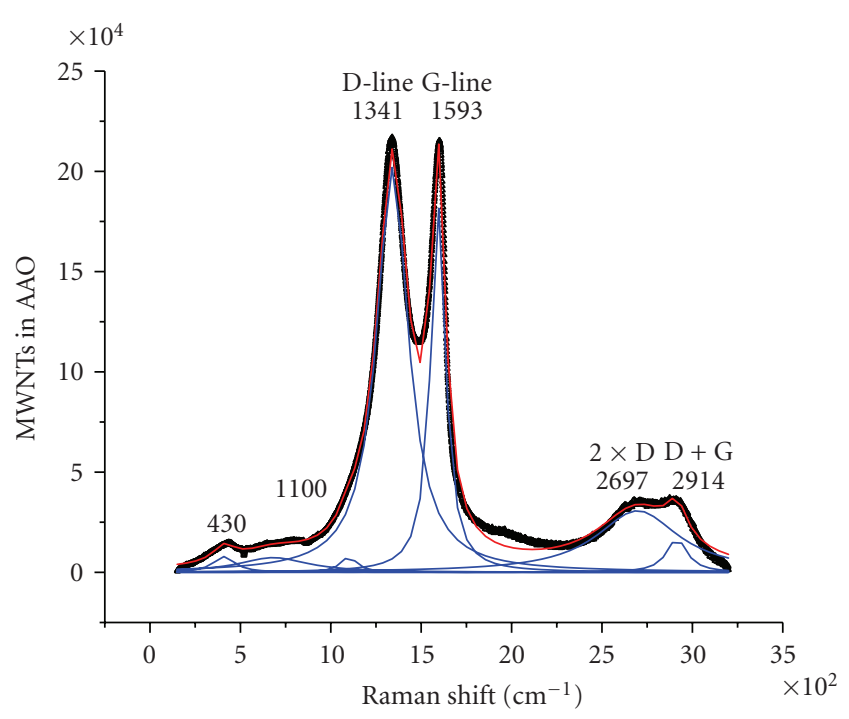

Figure 2: Analyzed MWNTs Raman spectrum with AAO background subtracted [black triangular dots (original Raman data), red trace (overall fit), and blue traces (individual scattering peaks)]. Broad unassigned peak around $650 \mathrm{~cm}^{-1}$ is due to incomplete background subtraction.

slight shiny luster. The Raman spectrum is shown in Figure 1. The first-order (below $2000 \mathrm{~cm}^{-1}$ ) and second-order (2000$4000 \mathrm{~cm}^{-1}$ ) Raman scattering peaks are clearly visible with the third-order peak (above $4000 \mathrm{~cm}^{-1}$ ) noticeable. The very broad background over the entire measurement range is due to luminescence from the AAO membrane as indicated in the AAO Raman spectrum in Figure 1. Upon background subtraction, the analyzed Raman spectrum is shown in Figure 2. The black dots are the experimental Raman data, and the red trace is the overall fitting with 7 Lorentzian peaks as indicated individually in blue traces. The strongest peaks are D- and G-lines at 1341 and $1593 \mathrm{~cm}^{-1}$, respectively. The D-line is due to the disordered $s p^{2}$ hybridized carbon, and the G-line is associated with the tangential stretching mode $\left(\mathrm{E}_{2 \mathrm{~g}}\right)$ of highly ordered pyrolytic graphite (HOPG) and indicates the presence of crystalline graphitic carbon in the MWNTs $[40,41]$. The second-order Raman peaks 
TABLE 2: Typical Raman scattering peaks for the MWNTs in this study.

\begin{tabular}{lcc}
\hline $\begin{array}{l}\text { Raman shift cm } \\
\text { This work (laser 633 nm) }\end{array}$ & $\begin{array}{c}\text { Raman shift cm } \\
\text { Reference [39] (laser 515 nm) }\end{array}$ & Peak assignments \\
\hline 430 & 450 & Large diameter NTs \\
1100 & 1100 & $\mathrm{D}$ \\
1341 & 1351 & $\mathrm{G}$ \\
1593 & 1590 & $2 \mathrm{D}$ \\
2697 (br) & 2701 & $\mathrm{D}+\mathrm{G}$ \\
2914 & 2934 & $2 \mathrm{G}$ \\
3192 & 3234 & $2 \mathrm{D}+\mathrm{G}(?)$ \\
4240 (br, w) & 4261 & \\
\hline
\end{tabular}

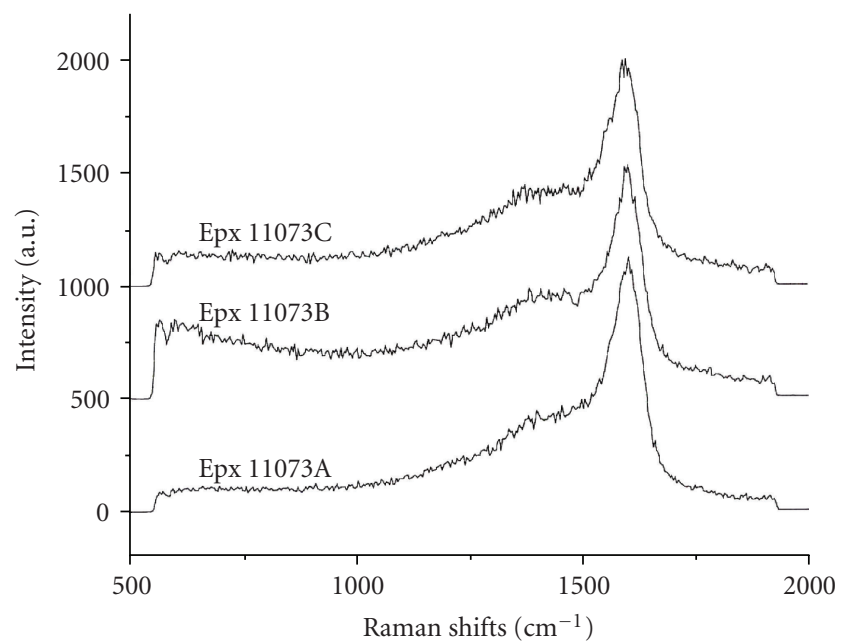

Figure 3: UV-Raman spectra of MWNTs in AAO template. The spectra are measured with frequency-doubled $(244 \mathrm{~nm})$ Ar laser excitation, $1 \mathrm{~cm}^{-1}$ resolution, and signal averaged over 10 scans.

corresponded to $2 \times \mathrm{D}$ (overtone), and $\mathrm{D}+\mathrm{G}$ (combination) have also been observed. The complete observed Raman peaks and their assignments compared to literature values are listed in Table 2. It is worth noting that a diameterindependent nanotube mode at $430 \mathrm{~cm}^{-1}$ is also consistently observed in our samples [40]. All observed Raman modes are in reasonably good agreement with literature values for MWNTs. The D-line and associated higher-order modes are lower than reported values in literature measured with different laser excitation (Table 2). This is likely due to the fact that the D-line is dispersive and its frequency is linearly laser excitation energy dependent. We have also carried out UV-Raman measurements (244 nm laser excitation) on these samples, and the results are shown in Figure 3. With UV excitation, the D-line is very broad and shifts to higher frequency $\left(>1400 \mathrm{~cm}^{-1}\right)$. Based on the large $D / G$ ratio observed with the visible laser excitation, the template confined carbonization of polymers also produces significant amount of disorder in the MWNTs as compared to those from the CVD method. Another observation worth noting is that when the MWNTs/AAO sample is cut, Raman measurements are carried out on the cross-section and the laser polarization is applied parallel and perpendicular to the expected MWNT axis direction, the perpendicular direction consistently gives $\sim 10 \%$ higher Raman peak intensity. This anisotropy strongly suggests the presence of aligned MWNTs and not disordered graphite.

3.2. SEM Characterization. The formation of polymer nanotubes and carbon nanotubes upon carbonization is directly studied with the use of field emission scanning electron microscopy. A five-minute epoxy polymer is used for the initial study. There are two components, the epoxy and curing agent, after the two components are mixed a drop of polymer is placed on a $230 \mathrm{~nm}$ AAO disk that is glued onto a $\mathrm{Cu}$ plate. The sample is heated at $140^{\circ} \mathrm{C}$ for 1 hour. After the polymer is fully cured, the template is removed by soaking and washing with $\mathrm{NaOH}$ solution, and the SEM image of the remaining polymer is shown in Figure 4(a). As revealed in the image, the epoxy polymer flows into the $230 \mathrm{~nm}$ pores very well. From this study also consistent with that reported in [36], majority of the observed nanoscale objects are polymer nanotubes. This is likely due to the stronger adhesive force than the cohesive force. Since the major component of the five-minute epoxy is bisphenol A, a few well-defined small molecular weight bisphenol A related polymers are used for the polymer nanotube carbonization study (Table 1 ). The epoxy coated AAO disk is heat treated at $2^{\circ} \mathrm{C} / \mathrm{min}$ to $500^{\circ} \mathrm{C}$, after template removal, the CNT bundle is shown in Figure 4(b). The top view and the close-in side view of these CNTs are shown in Figures $4(\mathrm{c})$ and 4(d), respectively. To explore whether the molten wetting procedure works for much smaller nanopores, we apply the same epoxy to home-made AAO membranes with 50 and $20 \mathrm{~nm}$ pore diameters. With the same heating rate at $2^{\circ} \mathrm{C} / \mathrm{min}$, the samples are heated to $600^{\circ} \mathrm{C}$ and hold for 3 hours. The results as shown in Figures $4(\mathrm{e})$ and 4(f) indicate that the method indeed works well for small nanopores.

For the commercial $230 \mathrm{~nm}$ pore diameter AAO disk, both ends of the nanopores are open. For the home-made AAO membranes, before the barrier layer is removed, one end is open and the other end is closed for all the nanopores [42]. Since open or closed ends play a crucial role for additional nanotube functionalization and/or tube filling, we 


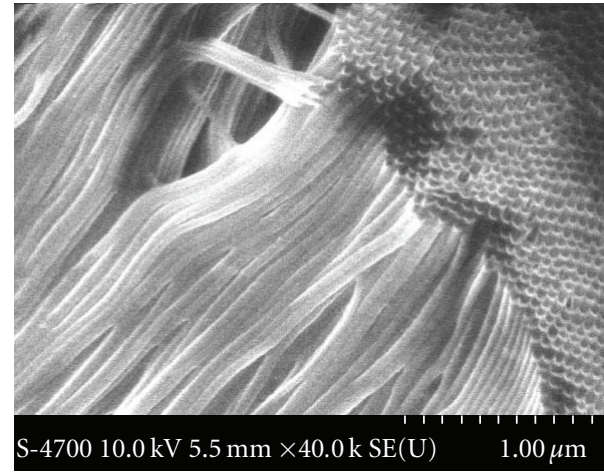

(a)

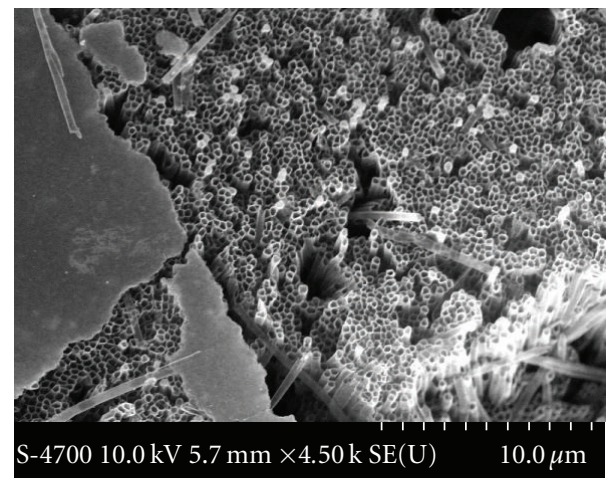

(c)

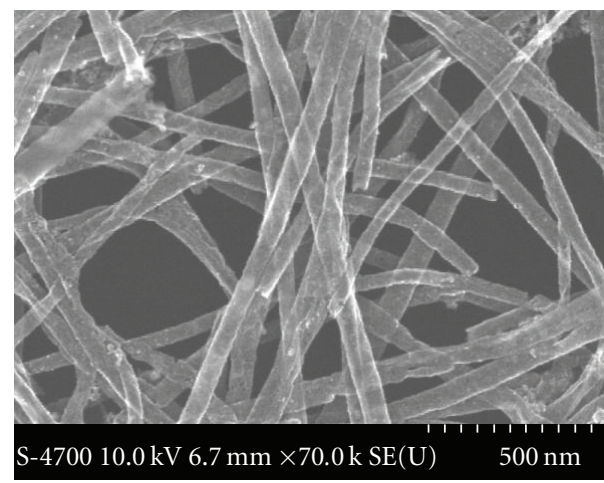

(e)

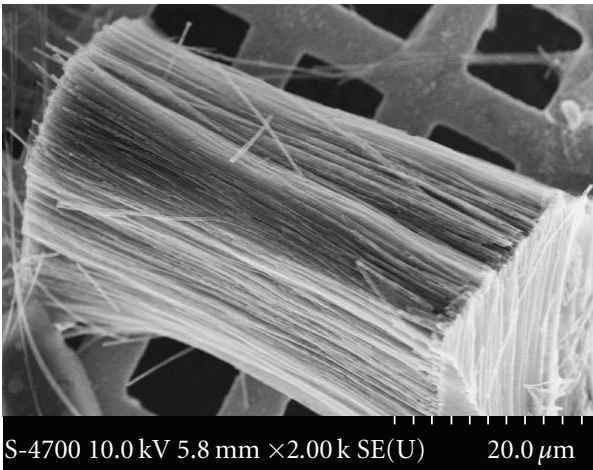

(b)

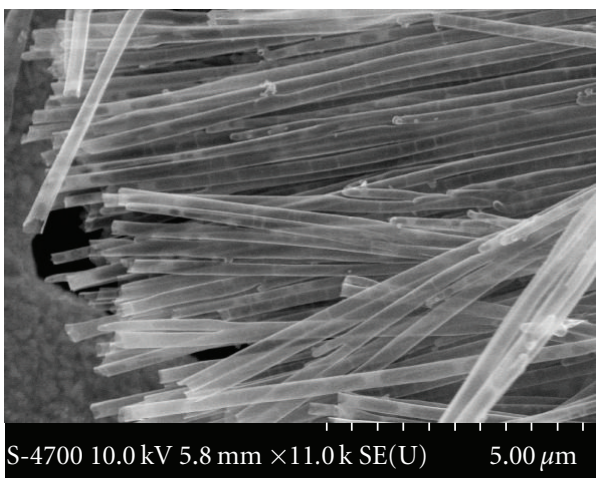

(d)

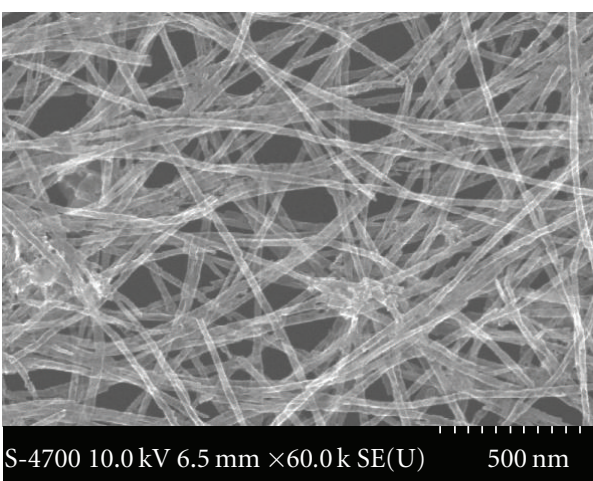

(f)

FIgURE 4: (a) The fully crosslinked epoxy nanotubes from a 5-minute epoxy, heated at $140^{\circ} \mathrm{C}$ for 1 hour and released from $\mathrm{AAO}$ template by dissolving the alumina in $1 \mathrm{M} \mathrm{NaOH}$ solution. (b) Bundle of $\mathrm{CNTs}$ after further carbonization at $500^{\circ} \mathrm{C}$ and being released from the pores of AAO template. (c) Top view of aligned MWNTs showing the pore opening. (d) Side view of MWNTs with diameter $\sim 230 \mathrm{~nm}$. (e) MWNTs with $50 \mathrm{~nm}$ diameter prepared from AAO template anodized from oxalic acid. (f) MWNTs with $20 \mathrm{~nm}$ diameter prepared from AAO template anodized from sulfuric acid.

look into the nature of the MWNTs prepared with our homemade AAO membranes in more details. The side view SEM images in Figures 4(e) and 4(f) of the MWNTs released from the templates do not provide conclusive answer. Therefore we remove the barrier layer by slow etching and image the back side directly. We use one piece of the MWNTs/AAO sample and glue the polymer filling side (open-end side) to a $\mathrm{Cu}$ foil. The sample is soaked in a $1 \mathrm{M} \mathrm{NaOH}$ solution at room temperature, and the sample is studied with the use of SEM at a fixed time increment. After 10 minutes etching, the barrier layer starts to open. The SEM image (Figure 5(a)) shows a large area view of AAO barrier side with imbedded MWNTs. After 15 minutes etching, the alumina barrier layer is removed. However, the end of each MWNT is still capped (Figure 5(b)). This is indicative of the materials at the end of the MWNT being etched at a much slower rate compared to that of the alumina barrier layer. Additional etching beyond 20 minutes only widens the nanopores, and individual MWNTs are standing in each pore and leaning toward each other (Figures 5(c) and 5(d)). 


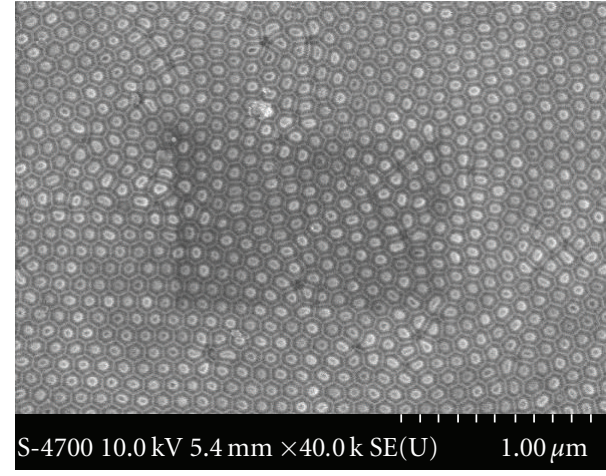

(a)

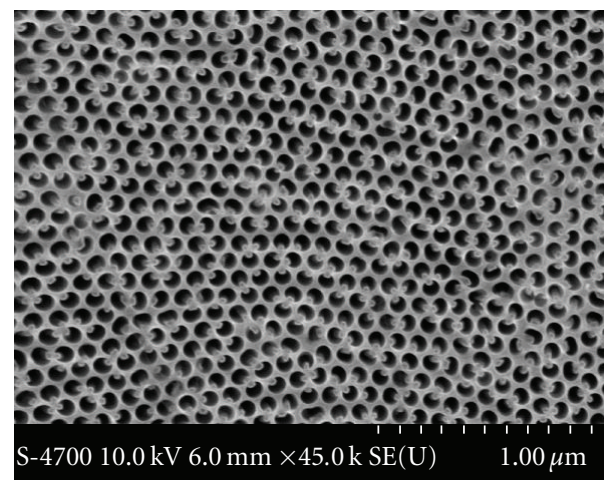

(c)

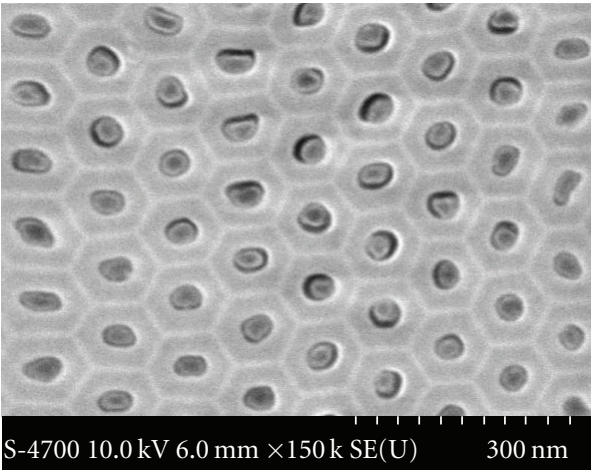

(b)

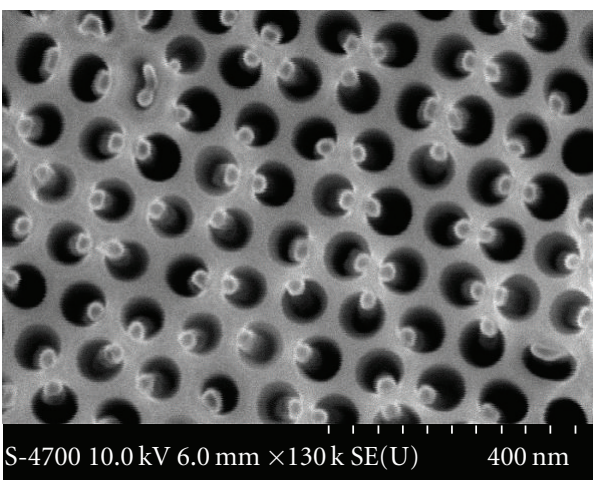

(d)

FIGURE 5: (a) SEM image of the barrier side of synthesized AAO membrane with $20 \mathrm{~nm}$ pores, Al removed, filled with carbonized MWNTs $\left(600^{\circ} \mathrm{C}\right)$, and etched the barrier layer for $10 \mathrm{~min}$. in $1 \mathrm{M} \mathrm{NaOH}$; (b) after $\sim 15 \mathrm{~min}$. etching MWNTs with caps start to detach from the pore walls; (c) after 20 min. etching, the pores are widened and MWNTs are standing in the pores; (d) same as (c) with higher magnification, the MWNT has a grayish center with bright rim indicates the cap still remains.

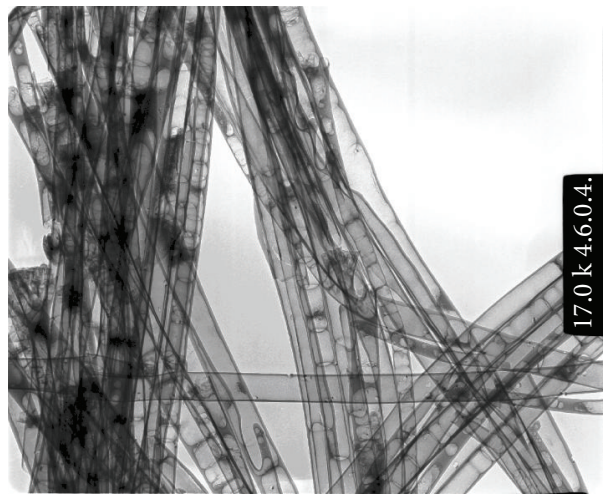

(a)

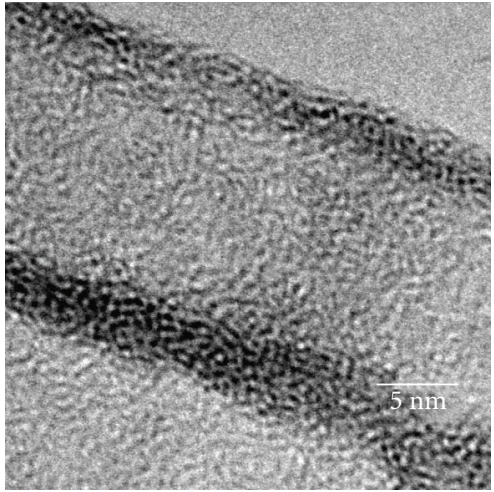

(b)

Figure 6: (a) TEM image of a MWNT bundle made from completely dissolving the AAO template (230 nm pores, $\left.500^{\circ} \mathrm{C}\right)$. (b) High magnification TEM image of a $20 \mathrm{~nm}$ MWNT prepared with slow heating to $600^{\circ} \mathrm{C}$.

As shown in Figure 5(d) the end of each MWNT is darker in the middle and brighter around the edge and does not appear to be a solid rod. Our result supports that during the melt-wetting process, the melts driven by adhesive force reach the bottom of the nanopores and form a conformal layer that upon carbonization leads to MWNTs with one end closed.
3.3. TEM Characterization. Additional sample characterization is carried out using transmission electron microscopy. Figure 6(a) shows a TEM image of a $230 \mathrm{~nm}$ carbon nanotube bundle which resulted from completely dissolving the AAO template. Electron diffraction patterns of all nanotubes were not of high quality. Many amorphous domains are observed but occasionally some graphitic characteristics are 


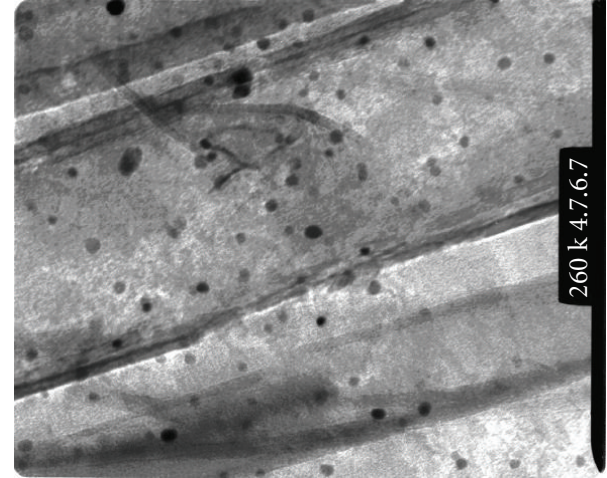

(a)

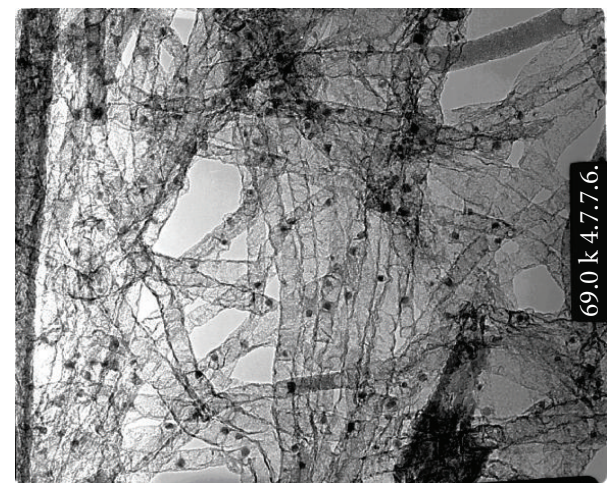

(b)

Figure 7: (a) CoPt nanoparticles (dark spots) with $6 \mathrm{~nm}$ diameter are successfully incorporated into $230 \mathrm{~nm}$ carbon nanotubes. (b) CoPt nanoparticles with $6 \mathrm{~nm}$ diameter are incorporated into $50 \mathrm{~nm}$ MWNTs with this procedure.

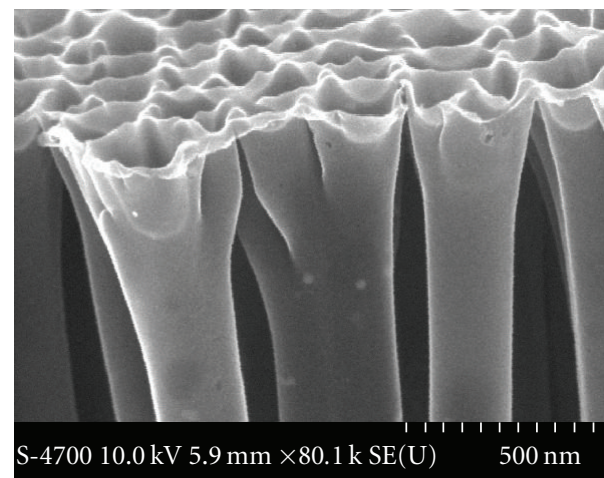

(a)

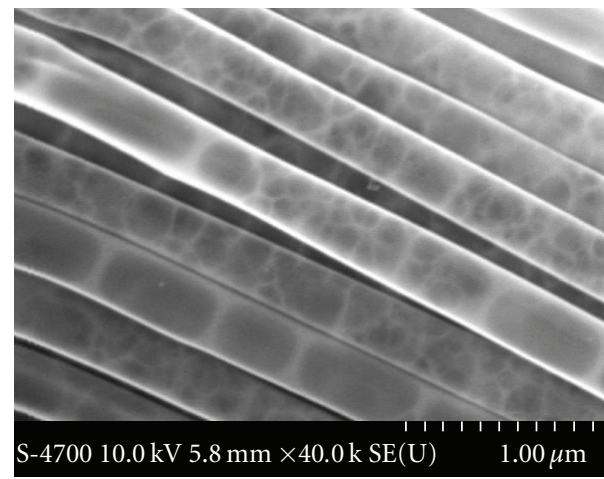

(c)

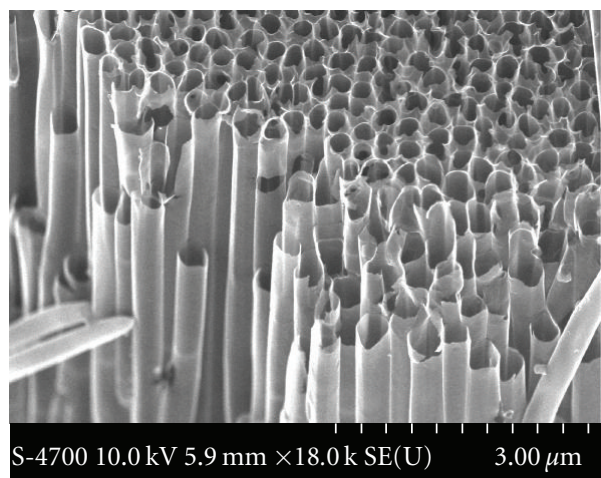

(b)

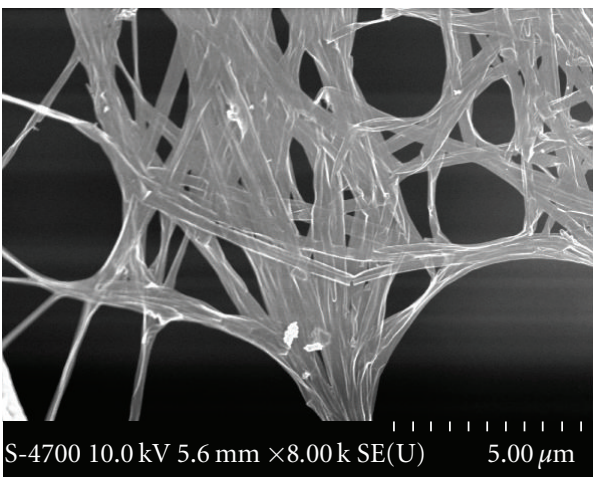

(d)

FIGURE 8: (a) Carbon nanotubes of various shapes can be made. Polymer nanotubes after carbonization at $500^{\circ} \mathrm{C}$ replicate the morphology of commercial AAO nanopores. (b) The nanotubes are parallel to each other and perpendicular to the template. They remain aligned when template is removed slowly. (c) Defects such as bubble formation in MWNTs may be trapped due to nonideal heat treatment condition. PS-co-PMMA is used in this case. (d) PS-b-poly(butadiene) precursor upon carbonization leads to flat and collapsed nanotubes.

revealed in some diffraction patterns: the brightest ring corresponds to the 002 reflection of hexagonal graphite and the next continuous ring seen in the diffraction pattern corresponds to the 110 reflection of hexagonal graphite. There is no difference in the intensity in this particular diffracted ring, which suggests that there is no preferred orientation along the $\mathrm{a}^{*}$ - or $\mathrm{b}^{*}$-axes [1]. A high-magnification TEM image of a
$20 \mathrm{~nm}$ CNT prepared from AAO template with slow heating to $600^{\circ} \mathrm{C}$ is shown in Figure 6(b). The tube wall thickness between 4 and $5 \mathrm{~nm}$ is visible from the image. Based on the interplanar separation in graphite $\left(\mathrm{d}_{002}=3.35 \AA\right)$, such tube wall thicknesses could accommodate approximately 12-15 graphitic shells [16]. 


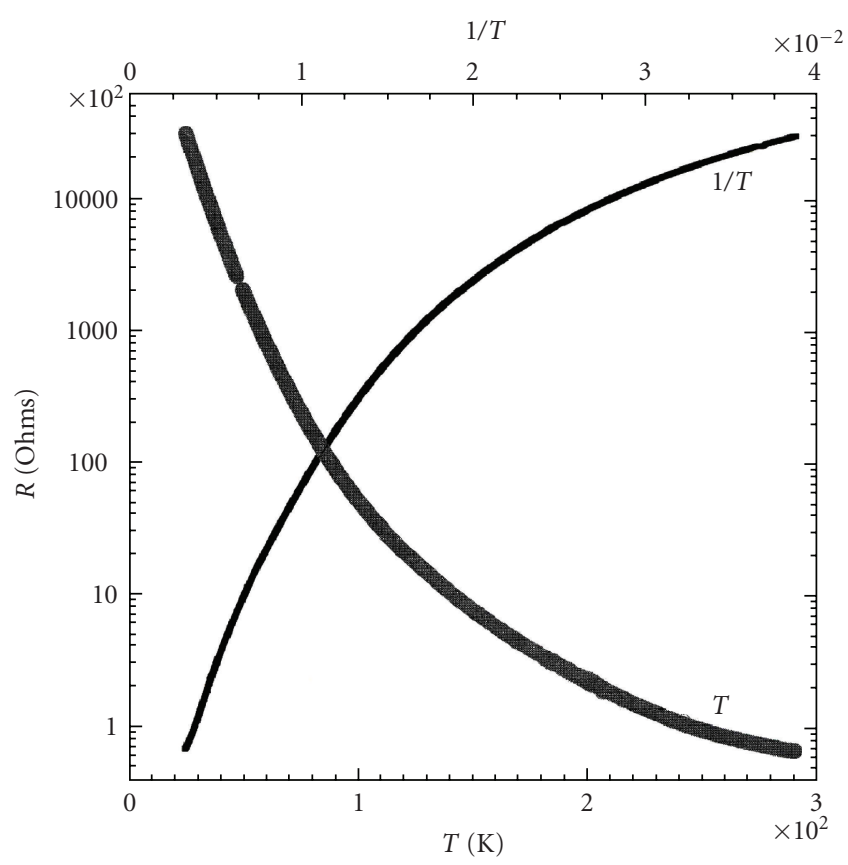

FIGURE 9: Resistive measurements made on a $50 \mathrm{~nm}$ CNT array $\left(600^{\circ} \mathrm{C}\right)$ imbedded in homemade AAO template by a two probe method show the characteristic of a semiconductor.

Another advantage of the current process is that it can be easily extended to prepare functionalized nanotubes by premixing any type of nanospecies such as nanoparticles or nanofibers with the polymer precursor, and then let the wetting process bring these nanospecies into the template channel to form various functional nanotubes. For example, CoPt nanoparticles with $6 \mathrm{~nm}$ diameter [43] are successfully incorporated into carbon nanotubes with diameters at 230 and $50 \mathrm{~nm}$ by this method (Figures 7(a) and $7(\mathrm{~b})$ ). Some aggregation is noticed as the incorporated nanoparticles appear to be slightly larger than $6 \mathrm{~nm}$; however, we demonstrate that this procedure brings nanoparticles into nanopores successfully without major aggregation of the nanoparticles upon heating, and this is a simple one-step method for such a complicated nanostructure. Apparently, the polymer matrix, viscosity, and low loading all help to avoid nanoparticle aggregation. Previously nanoparticles may have been loaded by multistep impregnation followed with reduction to prepare such functionalized nanostructure [34].

3.4. Nature and Effect of Polymer Precursors. When a polymer melt or solution is placed on a substrate with high surface energy, it will spread to form a thin film. Similar wetting phenomena occur if porous templates are brought into contact with polymer melts or solutions. A nanotube structure can be preserved if the wetting process is quenched at the initial stage since the wall wetting and complete filling of the pores take place at different time scales $[36,44]$. In our experiments, wetting of template wall happens on a time-scale of a few minutes when any liquid-form epoxy (e.g., a 5-minute epoxy) is used as starting materials. The fully crosslinked epoxy nanotubes are released from the AAO template by dissolving the alumina (Figure 4(a)). The epoxy tubes are of uniform diameter and length, with wall thickness of several tens of nanometers. It is found that the topography of the epoxy tubes matches the shape of their hosting pore channels so well that they can be used to duplicate the internal pore structure faithfully. Further carbonization process does not change the morphology of the epoxy nanotubes and their examination by electron microscopy technique can thus give a more reliable approach to study the pore structure since the carbonized nanotubes become conducting enough so that no additional carbon or metal coating is needed for imaging (Figure 8(a)). Since AAO membrane has recently attracted much attention for its application in nanotechnology, it is important to know the actual internal pore structure. AAO templates with pore diameter as small as $20 \mathrm{~nm}$ are also used for CNTs growth successfully (Figure 4(f)). The pore diameters can be increased or reduced by wet chemical etching [42] and atomic layer deposition method [45-48], respectively. The CNTs grown in the AAO template are very flexible and they can be bent at large angle $\left(>120^{\circ}\right)$ without being broken. The CNTs are of uniform length and the open-ended structure will facilitate their use in sensing applications as well as tube filling (Figure 8(b)) [3, 49-52].

All CNTs are of equal height and there is no overgrown problem normally happening in CVD growth. The nanotubes are parallel to each other, perpendicular to the template, and well-ordered to form a periodic triangular close-packed array without extra processing steps. The tube density, estimated from the pore density, can be as high as $4.4 \times 10^{10}$ pores $/ \mathrm{cm}^{2}$. The tube diameter distribution throughout the array is narrow, typically $10 \%$ of the main diameter-much narrower than heretofore reported using other methods of nanotube array synthesis. This CNT preparation process works for a large number of polymers we have tried (Table 1), except for polystyrene and polybisphenol A carbonate that decompose into styrene and bisphenol A, respectively [53, 54]. These small molecules evaporate completely and nothing is left after the carbonization process. It is found that carbon nanospecies with different morphology and/or structure can be produced when different polymer precursors are carbonized under the same reaction condition. For example, polystyreneco-polymethyl mathacrylate resulted in carbon nanotubes with many bubbles and sponge-like features (Figure 8(c)) and polystyrene-block-polybutadiene generated CNTs with very thin walls, so that they appear collapsed (Figure 8(d)). Fully collapsed carbon nanotubes have been reported in literature. For certain range of tube parameters, a completely collapsed nanotube is energetically more favorable [55]. A more recent article reported collapsed nanotubes due to poisoned metal catalyst that led to uneven carbon concentration and precipitation [56]. Since no catalyst is used in our study, the collapsed nanotubes may be related to the loss of styrene, a decomposed product from the block copolymers used that also leads to uneven carbon generation during carbonization. While there are remaining 
questions regarding the collapsed nanotubes formation from other polymers such as poly(acrylic acid), all observations of MWNTs and other morphology formation from various polymer precursors are summarized in Table 1.

The transport measurements made on a $50 \mathrm{~nm}$ CNT array imbedded in AAO template by a two probe method show the characteristic of a semiconductor (Figure 9). Even though CNTs can be made at temperatures as low as $400^{\circ} \mathrm{C}$, semiconductive behavior is observed only in samples made at temperatures above $600^{\circ} \mathrm{C}$. The resistance of MWNTs imbedded in $230 \mathrm{~nm}$ AAO membranes prepared at $600^{\circ} \mathrm{C}$ from different polymer precursors is measured with a twoprobe method across the membranes and ranges between 6 and $40 \mathrm{~K} \Omega$. Not well formed and collapsed carbon tubes give much higher resistance values between $300 \mathrm{~K} \Omega$ and $7 \mathrm{M} \Omega$. The results are also listed in Table 1 .

\section{Conclusion}

We report a simple, fast, one-step approach for the preparation of well aligned carbon nanotube array. Starting at very low temperature, $\sim 400^{\circ} \mathrm{C}$, the polymers are carbonized and graphitic nanotubes are generated. There is no flammable gas and catalyst involved, no monomer or polymer initiator is needed. The MWNTs duplicate the membrane nanopores precisely. For membranes with open ends on both sides, the resulting MWNTs contain the same open ends. For AAO membrane with closed barrier at one side, the resulting MWNTs contain one closed end. The open or closed ends of the MWNTs have strong implication for additional nanotube functionalization and/or filling. The template imbedded MWNTs of the same height are also ideal for nanoparticles filling. We demonstrated that CoPt nanoparticles can be filled along with the polymer nanotube precursor that can not be done with the CVD process. This method also allows post-synthesis nanoparticle filling. The MWNT and functionalized MWNT imbedded AAO membranes may find applications in catalysis reactions or catalyst support. The released MWNTs with combined semiconductive property and mechanical strength may be useful toward sensors and actuators. Finally, this method of MWNT array synthesis is not inherently area limited and can be scaled up with proper templates.

\section{Acknowledgments}

The work at Argonne National Laboratory and the electron microscopy accomplished at the Electron Microscopy Center for Materials Research are supported by UChicago Argonne, LLC, Operator of Argonne National Laboratory ("Argonne"). Argonne, a U.S. Department of Energy Office of Science laboratory, is operated under Contract no. DEAC02-06CH11357.

\section{References}

[1] S. Iijima, "Helical microtubules of graphitic carbon," Nature, vol. 354 , no. 6348 , pp. 56-58, 1991.
[2] M. S. Dresselhaus, G. Dresselhaus, and P. C. Eklund, Science of Fullerenes and Carbon Nanotubes, Academic Press, San Diego, Calif, USA, 1996.

[3] J. Kong, N. R. Franklin, C. Zhou, et al., "Nanotube molecular wires as chemical sensors," Science, vol. 287, no. 5453, pp. 622$625,2000$.

[4] R. H. Baughman, C. Cui, A. A. Zakhidov, et al., "Carbon nanotube actuators," Science, vol. 284, no. 5418, pp. 13401344, 1999.

[5] W. B. Choi, W. Park, E. J. Bae, et al., "Aligned carbon nanotubes for Nanoelectronics," Nanotechnology, vol. 15, pp. 512-516, 2004.

[6] A. G. Rinzler, J. H. Hafner, P. Nikolaev, et al., "Unraveling nanotubes: field emission from an atomic wire," Science, vol. 269, no. 5230, pp. 1550-1553, 1995.

[7] G. Che, B. B. Lakshmi, E. R. Fisher, and C. R. Martin, "Carbon nanotubule membranes for electrochemical energy storage and production," Nature, vol. 393, no. 6683, pp. 346-349, 1998.

[8] S. S. Wong, J. D. Harper, P. T. Lansbury Jr., and C. M. Lieber, "Carbon nanotube tips: high-resolution probes for imaging biological systems," Journal of the American Chemical Society, vol. 120, no. 3, pp. 603-604, 1998.

[9] H. Dai, J. H. Hafner, A. G. Rinzler, D. T. Colbert, and R. E. Smalley, "Nanotubes as nanoprobes in scanning probe microscopy," Nature, vol. 384, no. 6605, pp. 147-150, 1996.

[10] S. S. Wong, E. Joselevich, A. T. Woolley, C. L. Cheung, and C. M. Lieber, "Covalently functionalized nanotubes as nanometresized probes in chemistry and biology," Nature, vol. 394, no. 6688, pp. 52-55, 1998.

[11] R. Martel, T. Schmidt, H. R. Shea, T. Hertel, and P. Avouris, "Single- and multi-wall carbon nanotube field-effect transistors," Applied Physics Letters, vol. 73, no. 17, pp. 2447-2449, 1998.

[12] M. Ahlskog, R. Tarkiainen, L. Roschier, and P. Hakonen, "Single-electron transistor made of two crossing multiwalled carbon nanotubes and its noise properties," Applied Physics Letters, vol. 77, no. 24, pp. 4037-4039, 2000.

[13] L. Dai and A. W. H. Mau, "Controlled synthesis and modification of carbon nanotubes and C60: carbon nanostructures for advanced polymeric composite materials," Advanced Materials, vol. 13, no. 12-13, pp. 899-913, 2001.

[14] X. K. Wang, X. W. Lin, V. P. Dravid, J. B. Ketterson, and R. P. H. Chang, "Carbon nanotubes synthesized in a hydrogen arc discharge," Applied Physics Letters, vol. 66, no. 18, pp. 24302432, 1995.

[15] Y. Zhang and S. Iijima, "Formation of single-wall carbon nanotubes by laser ablation of fullerenes at low temperature," Applied Physics Letters, vol. 75, no. 20, pp. 3087-3089, 1999.

[16] J. Li, C. Papadopoulos, J. M. Xu, and M. Moskovits, "Highlyordered carbon nanotube arrays for electronics applications," Applied Physics Letters, vol. 75, no. 3, pp. 367-369, 1999.

[17] C. Journet, W. K. Maser, P. Bernier, et al., "Large-scale production of single-walled carbon nanotubes by the electricarc technique," Nature, vol. 388, no. 6644, pp. 756-758, 1997.

[18] A. Thess, R. Lee, P. Nikolaev, et al., "Crystalline ropes of metallic carbon nanotubes," Science, vol. 273, no. 5274, pp. 483-487, 1996.

[19] T. W. Ebbesen and P. M. Ajayan, "Large-scale synthesis of carbon nanotubes," Nature, vol. 358, no. 6383, pp. 220-222, 1992. 
[20] H. M. Cheng, F. Li, G. Su, et al., "Large-scale and low-cost synthesis of single-walled carbon nanotubes by the catalytic pyrolysis of hydrocarbons," Applied Physics Letters, vol. 72, no. 25, pp. 3282-3284, 1998.

[21] W. Hu, L. Yuan, Z. Chen, D. Gong, and K. Saito, "Fabrication and characterization of vertically aligned carbon nanotubes on silicon substrates using porous alumina nanotemplates," Journal of Nanoscience and Nanotechnology, vol. 2, no. 2, pp. 203-207, 2002.

[22] L. Yuan, K. Saito, W. Hu, and Z. Chen, "Ethylene flame synthesis of well-aligned multi-walled carbon nanotubes," Chemical Physics Letters, vol. 346, no. 1-2, pp. 23-28, 2001.

[23] L. Yuan, K. Saito, C. Pan, F. A. Williams, and A. S. Gordon, "Nanotubes from methane flames," Chemical Physics Letters, vol. 340, no. 3-4, pp. 237-241, 2001.

[24] K. Saito, F. A. Williams, and A. S. Gordon, "Structure of laminar coflow methane-air diffusion flames," Journal of Heat Transfer, vol. 108, no. 3, pp. 640-648, 1986.

[25] J. S. Suh and J. S. Lee, "Highly ordered two-dimensional carbon nanotube arrays," Applied Physics Letters, vol. 75, no. 14, pp. 2047-2049, 1999.

[26] T. Kyotani, L.-F. Tsai, and A. Tomita, "Formation of ultrafine carbon tubes by using an anodic aluminum oxide film as a template," Chemistry of Materials, vol. 7, no. 8, pp. 1427-1428, 1995.

[27] R. V. Parthasarathy, K. L. N. Phani, and C. R. Martin, “Template synthesis of graphitic nanotubules," Advanced Materials, vol. 7, no. 11, pp. 896-897, 1998.

[28] T. T. Xu, F. T. Fisher, L. C. Brinson, and R. S. Ruoff, "Boneshaped nanomaterials for nanocomposite applications," Nano Letters, vol. 3, no. 8, pp. 1135-1139, 2003.

[29] J. S. Suh, J. S. Lee, and H. Kim, "Linearly joined carbon nanotubes," Synthetic Metals, vol. 123, no. 3, pp. 381-383, 2001.

[30] J. S. Lee, G. H. Gu, H. Kim, K. S. Jeong, J. Bae, and J. S. Suh, "Growth of carbon nanotubes on anodic aluminum oxide templates: fabrication of a tube-in-tube and linearly joined tube," Chemistry of Materials, vol. 13, no. 7, pp. 2387-2391, 2001.

[31] J. Li, C. Papadopoulos, and J. Xu, "Growing Y-junction carbon nanotubes,” Nature, vol. 402, no. 6759, pp. 253-254, 1999.

[32] Y. Yang, Z. Hu, Q. Wu, Y. N. Lü, X. Z. Wang, and Y. Chen, "Template-confined growth and structural characterization of amorphous carbon nanotubes," Chemical Physics Letters, vol. 373, no. 5-6, pp. 580-585, 2003.

[33] R. V. Parthasarathy, K. L. N. Phani, and C. R. Martin, "Template synthesis of graphitic nanotubules," Advanced Materials, vol. 7, no. 11, pp. 896-897, 1995.

[34] T. Kyotani, B. K. Pradhan, and A. Tomita, "Synthesis of carbon nanotube composites in nanochannels of an anodic aluminum oxide film," Bulletin of the Chemical Society of Japan, vol. 72, no. 9, pp. 1957-1970, 1999.

[35] T. Kyotani, L.-F. Tsai, and A. Tomita, "Preparation of ultrafine carbon tubes in nanochannels of an anodic aluminum oxide film," Chemistry of Materials, vol. 8, no. 8, pp. 2109-2113, 1996.

[36] M. Steinhart, J. H. Wendorff, A. Greiner, et al., "Polymer nanotubes by wetting of ordered porous templates," Science, vol. 296, no. 5575, p. 1997, 2002.

[37] Z.-L. Xiao, C. Y. Han, U. Welp, et al., "Fabrication of alumina nanotubes and nanowires by etching porous alumina membranes," Nano Letters, vol. 2, no. 11, pp. 1293-1297, 2002.

[38] H. Masuda and M. Satoh, "Fabrication of gold nanodot array using anodic porous alumina as an evaporation mask,"
Japanese Journal of Applied Physics, Part 2, vol. 35, no. 1B, pp. L126-L129, 1996.

[39] H. Masuda, F. Hasegwa, and S. Ono, "Self-ordering of cell arrangement of anodic porous alumina formed in sulfuric acid solution," Journal of the Electrochemical Society, vol. 144, no. 5, pp. L127-L130, 1997.

[40] M. Sveningsson, R.-E. Morjan, O. A. Nerushev, et al., "Raman spectroscopy and field-emission properties of CVD-grown carbon-nanotube films," Applied Physics A, vol. 73, no. 4, pp. 409-418, 2001.

[41] M. S. Dresselhaus, G. Dresselhaus, A. Jorio, A. G. Souza Filho, and R. Saito, "Raman spectroscopy on isolated single wall carbon nanotubes," Carbon, vol. 40, no. 12, pp. 2043-2061, 2002.

[42] C. Y. Han, G. A. Willing, Z.-L. Xiao, and H. H. Wang, "Control of the anodic aluminum oxide barrier layer opening process by wet chemical etching," Langmuir, vol. 23, no. 3, pp. 1564-1568, 2007.

[43] A. C. S. Samia, J. A. Schlueter, J. S. Jiang, S. D. Bader, C.J. Qin, and X.-M. Lin, "Effect of ligand-metal interactions on the growth of transition-metal and alloy nanoparticles," Chemistry of Materials, vol. 18, no. 22, pp. 5203-5212, 2006.

[44] J. Jang, K. J. Lee, and Y. Kim, "Fabrication of polyimide nanotubes and carbon nanotubes containing magnetic iron oxide in confinement," Chemical Communications, no. 30, pp. 3847-3849, 2005.

[45] J. W. Elam, G. Xiong, C. Y. Han, et al., "Atomic layer deposition for the conformal coating of nanoporous materials," Journal of Nanomaterials, vol. 2006, Article ID 64501, 5 pages, 2006.

[46] J. W. Elam, A. Zinovev, C. Y. Han, et al., "Atomic layer deposition of palladium films on $\mathrm{Al}_{2} \mathrm{O}_{3}$ surfaces," Thin Solid Films, vol. 515, no. 4, pp. 1664-1673, 2006.

[47] G. Xiong, J. W. Elam, H. Feng, et al., "Effect of atomic layer deposition coatings on the surface structure of anodic aluminum oxide membranes," Journal of Physical Chemistry B, vol. 109, no. 29, pp. 14059-14063, 2005.

[48] M. J. Pellin, P. C. Stair, G. Xiong, et al., "Mesoporous catalytic membranes: synthetic control of pore size and wall composition," Catalysis Letters, vol. 102, no. 3-4, pp. 127-130, 2005.

[49] P. G. Collins, K. Bradley, M. Ishigami, and A. Zettl, "Extreme oxygen sensitivity of electronic properties of carbon nanotubes," Science, vol. 287, no. 5459, pp. 1801-1804, 2000.

[50] J. Kong, M. G. Chapline, and H. Dai, "Functionalized carbon nanotubes for molecular hydrogen sensors," Advanced Materials, vol. 13, no. 18, pp. 1384-1386, 2001.

[51] A. V. Bazilevsky, K. Sun, A. L. Yarin, and C. M. Megaridis, "Selective intercalation of polymers in carbon nanotubes," Langmuir, vol. 23, no. 14, pp. 7451-7455, 2007.

[52] A. V. Bazilevsky, K. Sun, A. L. Yarin, and C. M. Megaridis, "Room-temperature, open-air, wet intercalation of liquids, surfactants, polymers and nanoparticles within nanotubes and microchannels," Journal of Materials Chemistry, vol. 18, no. 6, pp. 696-702, 2008.

[53] C. Puglisi, F. Samperi, S. Carroccio, and G. Montaudo, "Maldi-top investigation of polymer degradation. Pyrolysis of poly(bisphenol a carbonate)," Macromolecules, vol. 32, no. 26, pp. 8821-8828, 1999.

[54] J. D. Peterson, S. Vyazovkin, and C. A. Wight, "Kinetics of the thermal and thermo-oxidative degradation of polystyrene, polyethylene and poly(propylene)," Macromolecular Chemistry and Physics, vol. 202, no. 6, pp. 775-784, 2001. 
[55] N. G. Chopra, L. X. Benedict, V. H. Crespi, M. L. Cohen, S. G. Louie, and A. Zettl, "Fully collapsed carbon nanotubes," Nature, vol. 377, no. 6545, pp. 135-138, 1995.

[56] W. Qian, F. Wei, T. Liu, Z. Wang, and Y. Li, "What causes the carbon nanotubes collapse in a chemical vapor deposition process," Journal of Chemical Physics, vol. 118, no. 2, pp. 878$882,2003$. 

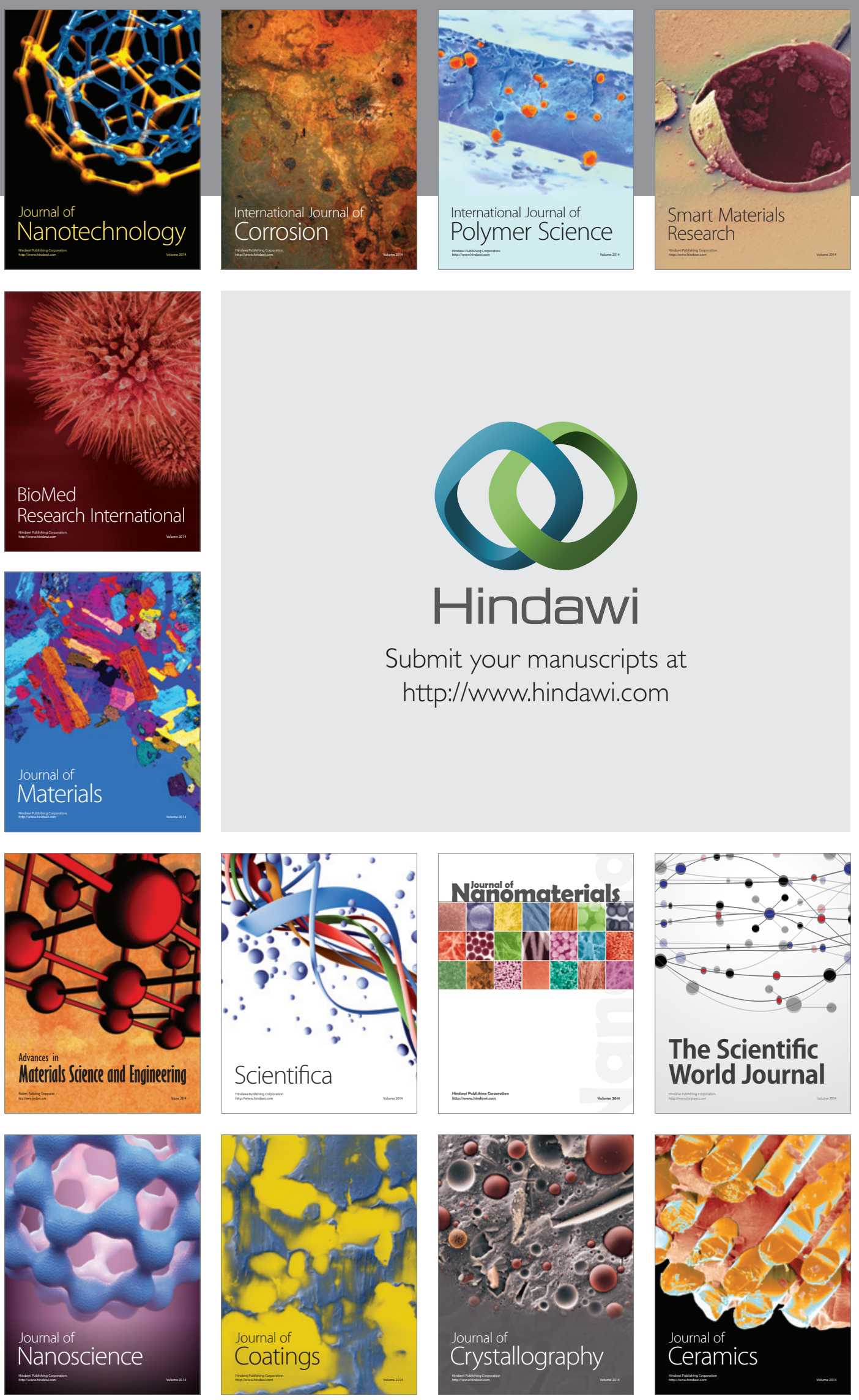

The Scientific World Journal

Submit your manuscripts at

http://www.hindawi.com

\section{World Journal}

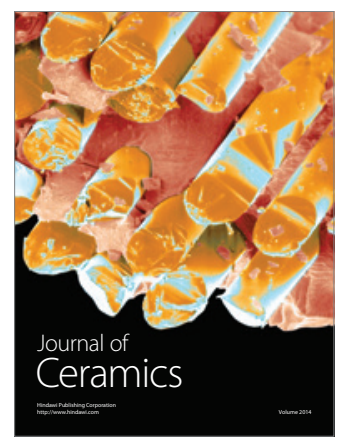

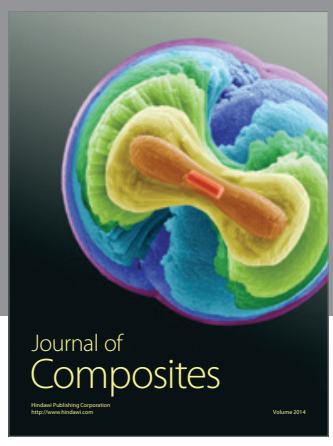
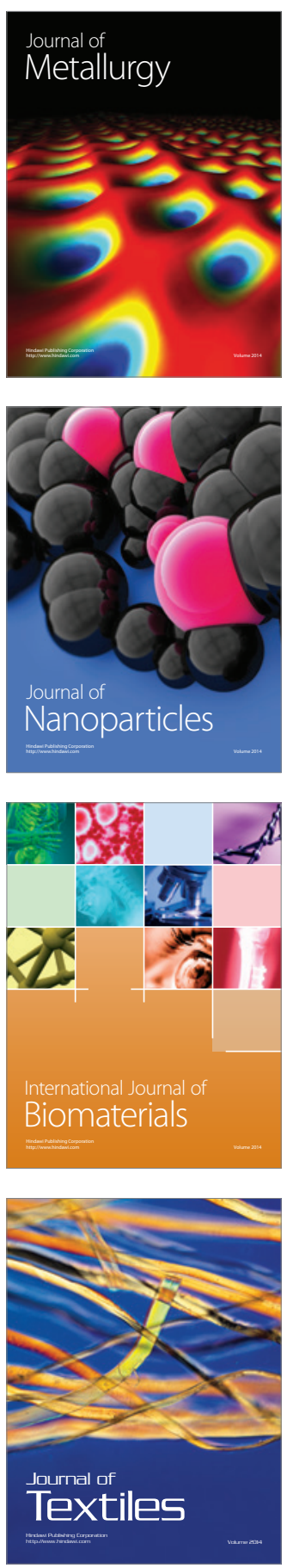